\title{
Following Mixed Tree Nut Biscuit Challenge, Are the Nuts Still Included in the Diet?
}

\author{
Benedicta Itotoh $^{1}$ (D) - Ingrid Roche ${ }^{1} \cdot$ Catherine Power $^{1}$
}

Accepted: 24 August 2020 / Published online: 7 September 2020

(C) The Author(s) 2020

\begin{abstract}
We studied the introduction rate after a negative challenge to mixed tree nut biscuit. This is a retrospective review of patients who underwent and passed mixed tree nut biscuit challenges performed at Princess Margaret Hospital (PMH) between 2016 and 2018. Follow-up phone calls were made to families to ascertain if the tree nuts included in the tree nut biscuit were still included in the child's diet 1 to 3 years following negative oral food challenge (OFC). A total of 162 children underwent mixed tree nut biscuit challenge between 2016 and 2018 at Princess Margaret Hospital, Perth, Western Australia. A total of 141 (87\%) passed mixed tree nut biscuit challenge. Of the 133 children that were contacted ( 8 children could not be contacted), 104 children still included some or all of the challenge nuts in the child's diet; with 24 children completely eliminating the challenge nuts (18\%), 5 children eliminated some of the challenge nuts $(3.5 \%)$. We found a high introduction rate $(82 \%)$; however, some families may require more support to maintain the tree nuts in the child's diet following a negative OFC.
\end{abstract}

Keywords Mixed tree nut challenge

To the Editor

Undiagnosed food allergy without known reaction to the avoided food could result in elimination of the suspected food from a child's diet [1]. Performing OFC to individual tree nuts is time consuming and impractical. Following a negative OFC children need to regularly include that food in their diet with evidence showing this may help to maintain tolerance to that food [2].

\section{Introduction}

We studied the dietary introduction rate of tree nuts following a negative OFC. Most of the children avoided tree nuts because they were allergic to other foods or sensitized to tree nuts with no known clinical reaction. Some were avoiding tree nuts because another family member has a nut allergy.

This article is part of the Topical Collection on Medicine

Benedicta Itotoh

benedicta.itotoh@health.wa.gov.au

1 Department of Immunology, Perth Children's Hospital, Nedlands, Western Australia, Australia

\section{Materials and Methods}

The patients in this study are from a retrospective review of patients with a negative OFC to mixed tree nut biscuit performed at Princess Margaret Hospital (PMH), Western Australia between 2016 and 2018.

The tree nuts used in the OFC are almond, Brazil nut, macadamia, cashew, pistachio, walnut, pecan, hazel nut, pine nut, and coconut. Mixed tree nut biscuit OFC included at least 2 of the above nuts.

The cohort of patients had predominantly negative or low positive skin prick test $(<6$-mm mean skin prick test weal diameter). Although most of the patients had a negative skin prick test (SPT), the challenge was done in hospital as families were anxious or reluctant to introduce the nuts at home.

The SPT was performed and read as per the published guidelines of the Australasian Society of Clinical Immunology and Allergy [3]. The SPT size on the day of the challenge was recorded.

The treating physician decides what nuts were included in the biscuit, and the patient's family baked and provided the mixed tree nut biscuit according to the recipe provided by the PMH Immunology Department. The biscuit was then administered in a 5 -step procedure starting with 1/16, 1/8, 1/4, 1/2, and the reminder of the biscuit given at 15-min intervals if challenge was performed in the outpatient department 
Table 1 Possible factors associated with failed introduction following negative OFC to three nuts

\begin{tabular}{|c|c|c|c|}
\hline & $\begin{array}{l}\text { Successful } \\
\text { (eating all nuts }\end{array}$ & $\begin{array}{l}\text { Partial (eating } \\
\text { some nuts) }\end{array}$ & $\begin{array}{l}\text { Unsuccessful } \\
\text { (not eating any } \\
\text { of the nuts) }\end{array}$ \\
\hline Total & 104 & 5 & 24 \\
\hline \multicolumn{4}{|l|}{ Gender } \\
\hline Male & 65 & 3 & 8 \\
\hline Female & 39 & 2 & 16 \\
\hline Age range & $\begin{array}{l}1 \text { year } \\
5 \text { months to } \\
17 \text { years } \\
7 \text { months }\end{array}$ & $\begin{array}{l}1 \text { year } \\
8 \text { months to } \\
10 \text { years } \\
4 \text { months }\end{array}$ & $\begin{array}{l}1 \text { year } \\
8 \text { months to } \\
16 \text { years }\end{array}$ \\
\hline $\begin{array}{l}\text { Symptoms to } \\
\text { challenged nuts } \\
\text { following } \\
\text { successful OFC }\end{array}$ & 0 & $\begin{array}{l}1 \\
\text { Hives to hazel } \\
\text { nut }\end{array}$ & $\begin{array}{l}1 \\
\text { Respiratory } \\
\text { symptoms }\end{array}$ \\
\hline
\end{tabular}

(OPD) or as a 7-step procedure starting with 1/64, 1/32, 1/16, $1 / 8,1 / 4,1 / 2$, and reminder of the biscuit given at 20-min intervals if challenge was performed in the day procedure unit (DPU). The decision to either perform the challenge in the OPD or DPU was determined by the treating physician based on the clinical risk of allergic reaction. Eight grams of each challenge nut were included in the biscuit.

Signed consent for the challenge was obtained from the parents prior to the challenge.

Patients were recorded as a positive OFC if there were objective signs of an IgE-mediated reaction as follows: angioedema, generalized skin erythema, stridor, cough, wheeze, at least 3 or more noncontact urticaria persisting for $5 \mathrm{~min}$ or more, rhinoconjunctivitis, abdominal pain, vomiting, and hypotension [4]. All patients had follow-up phone contact 24 weeks following the OFC. The patients were termed tolerant if they had a negative OFC and were tolerating the nuts at their 2-4-week follow-up phone calls. Patients that passed the challenge were advised to continue eating the nuts included in the biscuit regularly (at least weekly).
Data was obtained from electronic patient records as well as patient charts and used in strictly anonymous form, according to the code of conduct for medical research approved by the hospital's Medical Ethical Committee (Child and Adolescent Health Service Safety and Quality Committee).

\section{Results}

A total of 162 children underwent mixed tree nut biscuit OFC between 2016 and 2018 at PMH. A total of 141 passed mixed tree nut biscuit challenge (87\%). The majority of OFCs were conducted in the OPD (70.4\%). All 141 patient charts were examined with follow-up phone calls made to families to ascertain if the nuts were still included in the child's diet $1-$ 3 years following the OFC. Eight families could not be contacted. The majority were male (55\%). Median age at challenge was 8 years and 5 months (range 1 year and 7 months to 17 years and 7 months). Twenty-seven children were administered six nut challenge, 40 underwent 5 nut challenge, 38 had 4 nut challenge, 23 had 3 nut challenge, and 13 patients had 2 nut challenge.

Of the 133 families that were contacted, 104 families still included some or all of the challenge nuts in the child's diet. Twenty-four patients completely eliminated the challenge nuts $(18 \%)$ and 5 patients eliminated some of the challenge nuts $(3.5 \%)$.

\section{Discussion}

Possible factors influencing the introduction of the challenge nuts in the diet are shown in Table 1. Other patient characteristics with successful, partial, and unsuccessful challenge nut dietary introduction are shown in Table 1 . There are no statistically relevant differences between the three groups.
Fig. 1 Reasons for eliminating nuts from diet

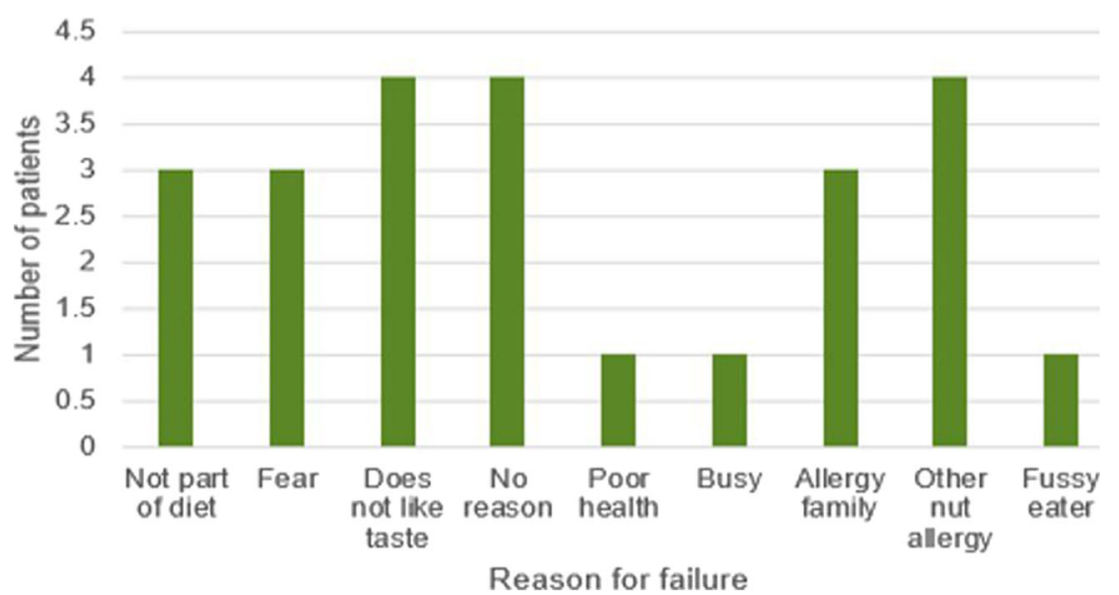

SN Comprehensive Clinical Medicine 
Table 2 Tree nuts included in biscuit, rate of introduction, and elimination from diet

\begin{tabular}{lcll}
\hline & $\begin{array}{l}\text { Nuts included in } \\
\text { mixed tree nut } \\
\text { biscuit }\end{array}$ & $\begin{array}{l}\text { Nuts eliminated } \\
\text { from diet following } \\
\text { OFC }\end{array}$ & $\begin{array}{l}\text { Nuts maintained } \\
\text { in diet following } \\
\text { OFC }\end{array}$ \\
\hline Almond & 97 & 21 & 77 \\
Brazil nut & 97 & 21 & 76 \\
Macadamia & 114 & 21 & 76 \\
Hazel nut & 66 & 13 & 53 \\
Pecan & 17 & 1 & 16 \\
Walnut & 76 & 17 & 59 \\
Cashew & 50 & 9 & 41 \\
Pistachio & 6 & 1 & 5 \\
Pine nut & 23 & 5 & 18 \\
Coconut & & & \\
\hline
\end{tabular}

The reasons for the 24 families who completely eliminated the challenge nuts from the child's diet, in spite of a negative OFC, are depicted in Fig. 1.

Review of Fig. 1 shows 3 children being scared to continue eating the challenge nuts; 4 children being diagnosed with another nut allergy that was not included in the OFC so the family choose to avoid all nuts; 1 child being busy with final year of high school; and another child having general poor health.

More boys (90\%) than girls (83\%) had partially or successfully introduced the nuts. Of those that continued to eat the nuts, all but 2 families reported there was no reactions to any of the nuts. One family reported that the child developed hives secondary to hazel nut exposure. This child had OFC performed which included almond, hazel nut, Brazil nut, macadamia, and pine nut with the following SPTs: Almond, Brazil nut, and macadamia are all negative SPT. Hazel nut SPT was $4 \times 4 \mathrm{~mm}$. Pine nut SPT was $3 \times 3 \mathrm{~mm}$.
The other family describes exacerbation of the child's asthma to all nuts. However, there was no clinical correlation between exposure to nuts and exacerbation of asthma with the elimination of nuts having no impact on the asthma symptoms. This patient was challenged to almond, Brazil nut, walnut (negative SPT), hazel nut $(2 \times 2 \mathrm{~mm} \mathrm{SPT})$, and macadamia nut $(1 \times 1 \mathrm{~mm} \mathrm{SPT})$.

Of the 5 children whose families partially introduced the tree nuts, we note the following:

The first child is the same child that excluded hazel nut because she had hives to hazel nut. She retained almond, Brazil, macadamia, and pine nuts in her diet.

Two children ate almond only for no defined reason. One child had challenge to almond, Brazil nut, walnut, and macadamia, while the other child had challenge to almond, macadamia, Brazil, hazel, and pine nuts.

One child retained 2 of the 4 nuts included in their biscuit challenge (hazel and macadamia nuts) with the remaining nuts (brazil and cashew nuts) excluded as this child is reported to be a "fussy eater" by parents.

The last child retained 3 of the 5 nuts included in their biscuit challenge (almond, hazel, and macadamia nuts) with the remaining nuts (brazil and walnut) excluded based on taste.

Average number of tree nuts in challenges was four. Macadamia was the most frequently included tree nut in the OFC. Table 2 is a representation of the tree nuts included in the biscuit and tree nuts eliminated or maintained in the diet following OFC. Just as macadamia, almond, and Brazil nuts were most likely to be maintained in the diet, they also had high rates of elimination from diet which may be a reflection of the frequency these nuts were included in the OFC.

SPT ranged from negative to $7 \times 5 \mathrm{~mm}$ prior to the test. SPT was done for all nuts included in the biscuit. Figure 2 is a representation of the SPT performed prior to the challenge.

Previous reaction to tree nuts included in the biscuit range from none (sensitized only with no previous exposure) to objective symptoms as well as nonobjective symptoms.
Fig. 2 SPT prior to OFC

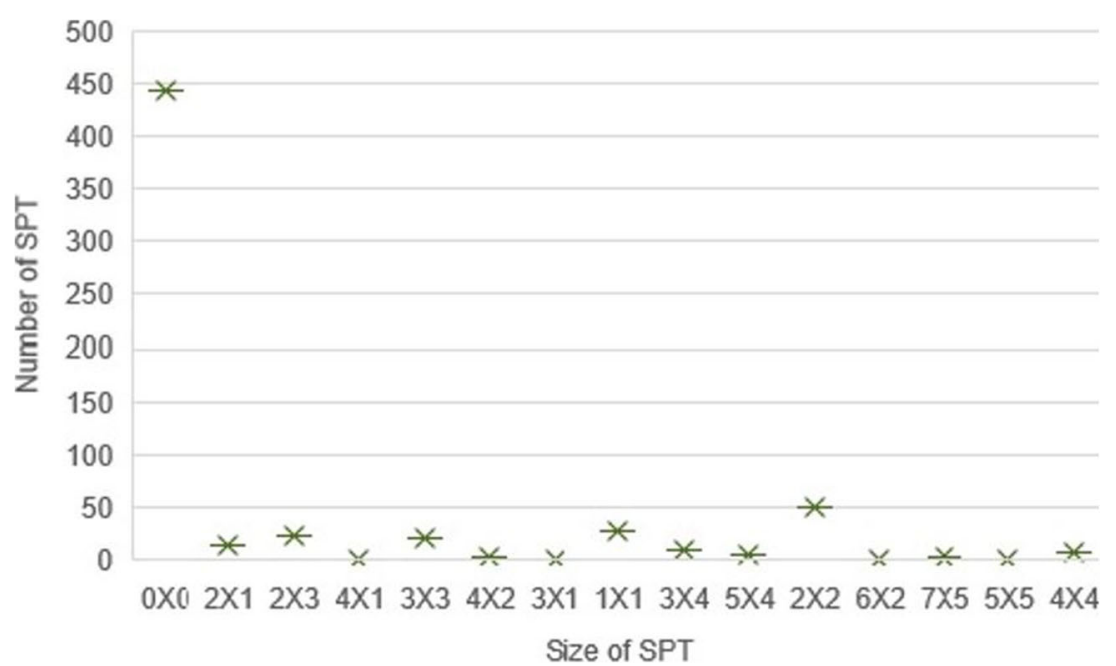


Table 3 Symptoms to nuts included in biscuits prior to OFC, SPT on day, and outcome on follow-up

\begin{tabular}{|c|c|c|c|c|}
\hline Patients (age and gender) & $\begin{array}{l}\text { Symptoms to nuts in biscuits } \\
\text { prior to OFC }\end{array}$ & Nuts included in biscuits & $\begin{array}{l}\text { SPT to nuts on the } \\
\text { day of OFC }\end{array}$ & Outcome on follow-up \\
\hline $\begin{array}{l}\text { Male } \\
8 \text { years } 6 \text { months }\end{array}$ & Upper respiratory symptoms & Almond, pine nut, macadamia & Negative to all & All nuts maintained in diet \\
\hline $\begin{array}{l}\text { Male } \\
2 \text { years } 10 \text { months }\end{array}$ & Generalized rash & Almond, Brazil nut, cashew & Negative to all & All nuts maintained in diet \\
\hline Female 12 years 1 month & Throat tightness & $\begin{array}{l}\text { Almond, hazel nut, Brazil nut, } \\
\text { cashew, macadamia }\end{array}$ & Negative to all & $\begin{array}{l}\text { None of the nuts maintained } \\
\text { in diet, no reason given }\end{array}$ \\
\hline Female 13 years 6 months & $\begin{array}{l}\text { Urticaria to products labeled } \\
\text { may contain traces }\end{array}$ & $\begin{array}{l}\text { Almond, Brazil nut, walnut, } \\
\text { Macadamia }\end{array}$ & $\begin{array}{l}\text { Almond }(3 \times 4 \mathrm{~mm}) \\
\text { Brazil nut }(2 \times 4 \mathrm{~mm}) \\
\text { walnut negative } \\
\text { Macadamia }(3 \times 3 \mathrm{~mm})\end{array}$ & All nuts maintained in diet \\
\hline Female 3 years 2 months & Facial rash, itchy tongue & $\begin{array}{l}\text { Almond, Brazil nut, cashew, } \\
\text { walnut, macadamia }\end{array}$ & Negative to all & All nuts maintained in diet \\
\hline $\begin{array}{l}\text { Male } \\
13 \text { years } 10 \text { months }\end{array}$ & Facial erythema to pine nuts & Brazil nut, pine nut, macadamia & $\begin{array}{l}\text { Brazil nut } 4 \times 5 \mathrm{~mm} \\
\text { Macadamia } 2 \times 3 \mathrm{~mm} \\
\text { Pine nut negative }\end{array}$ & All nuts maintained in diet \\
\hline
\end{tabular}

Of all the 139 who had negative OFC, 6 describe symptoms to the challenge nuts prior to the challenge. Characteristics of this group are reflected in Table 3.

The presence of asthma, eczema, allergic rhinitis, and other food allergies was determined in out-patient clinic consultation before the OFC. This information is detailed in Table 4.

Most of the patients that passed the challenge had multiple food allergies. There were 256 cases of documented single or multiple food allergies. Of these 64 are allergic to peanuts, 58 allergic to other tree nuts not included in the OFC, 47 allergic to egg, 18 allergic to cow's milk, and 69 allergic to other foods (wheat, other legumes, sesame, sea food, and kiwi fruit).

Previous study by Van Der Valk et al. looked at introduction of cashew nut following a negative OFC at 6 months with a successful introduction rate of $43.3 \%$ [5]. Our study found a combined total of successful and partial introduction rate of $82 \%$ for all challenge nuts.

There are some limitations to our study. It is a retrospective study which relied on the documentation of the treating physician. We also note the majority of patients had negative or low positive SPT which is not representative of patients with true tree nut allergy. The families prepared the tree nut biscuit as per our guidelines though this is not standardized with all tested tree nuts.

Table 4 Patient characteristics for successful, partially successful, and unsuccessful introduction of tree nuts

\begin{tabular}{lcll}
\hline & Successful & Partially successful & Unsuccessful \\
\hline Eczema & 25 & 1 & 7 \\
Asthma & 25 & 0 & 5 \\
Allergic rhinitis & 21 & 1 & 4 \\
Other tree nut allergy & 50 & 3 & 5 \\
Peanut allergy & 53 & 3 & 8 \\
Other food allergy & 111 & 2 & 21 \\
\hline
\end{tabular}

Our study reveals that there is a high success rate of passing the mixed tree nut OFC with the majority of families continuing to eat the nuts. Recurrence of tree nut allergy following OFC has not been reported to date.

It will be interesting to follow up children that failed the introduction of the challenge nuts to note if immunologic tolerance is maintained.

To further improve rates of introduction of the tree nuts following negative OFC, we should encourage families to maintain the nuts in the child's diet. Contact between families and the Immunology Department should be streamlined to allow contemporaneous contact at the time of a possible reaction to the challenge nuts.

\section{Conclusion}

Our data show that open mixed tree nut OFC is useful in excluding multiple tree nut allergies in children with low suspicion of clinical allergy. Some families will require more support to maintain the challenge nuts in the child's diet following a negative OFC.

Authors' Contribution Authors 1, 2, and 3 contributed to the conception and design of the work and acquisition, analysis, and interpretation of data and also contributed to drafting the work and revising it critically for important intellectual content as well as final approval of the version to be published. All authors agree to be accountable for all aspects of the work in ensuring that questions related to the accuracy or integrity of any part of the work are appropriately investigated and resolved.

\section{Compliance with Ethical Standards}

Conflict of Interest The authors declare that they have no conflict of interest. 
Ethical Approval Data was obtained from electronic patient records as well as patient charts and used in strictly anonymous form, according to the code of conduct for medical research approved by the hospital's Medical Ethical Committee (Child and Adolescent Health Service Safety and Quality Committee).

Informed Consent Signed consent for the challenge was obtained from the parents prior to the challenge. In accordance with the hospital's guidelines for use of patient's records, data was obtained from electronic patient records as well as patient charts and used in strictly anonymous form. Verbal consent was obtained from the parent prior to commencing the phone interview.

\section{Appendix}

Recipe for mixed tree nut biscuit.

\title{
Mixed Nut Biscuit recipe will make one large biscuit):
}

Nuts to be included in the biscuit (Dr to tick boxes of nuts to be included and cross out others):

\author{
$\square 5$ whole Almonds or $8 \mathrm{~g}$ of almond meal \\ $\checkmark 7$ whole Hazelnuts or $8 \mathrm{~g}$ of hazelnut meal \\ $\square 2$ whole Brazil nuts \\ 7 whole Cashew nuts \\ 口 3 small Walnut halves \\ ๑ 7 Macadamia halves
}

\section{To bake this biscuit you will need:}

1. 1 level tablespoon of self raising flour (approx $20 \mathrm{~g}$ )

(if allergic to wheat, use appropriate flour - like soy, rice.....)

2. 1 level teaspoon of margarine (approx $5 \mathrm{~g}$ )

3. $11 / 2$ teaspoons of Castor sugar (approx $6 \mathrm{~g}$ )

4. $1 / 2$ teaspoon of golden syrup (approx $3 \mathrm{~g}$ )

5. Nuts in the quantities as listed above (only include nuts that are ticked)

6. 1-2 flat teaspoons of water to mix

NB: for flavour you can substitute $10 \mathrm{~g}$ of self raising flour with $10 \mathrm{~g}$ of Cocoa powder

Preparation instructions: (Ensure all equipment is clean and free from contamination)

1. Pre-heat conventional oven to $200^{\circ} \mathrm{C}$

2. Grind whole nuts to a coarse powder by using an electric grinder, thermomix or manually grinding the nuts with a pestle and mortar or a cheese grater. Remove and regrind any chunks so you will have a mixed nut meal or paste in the end

3. Place flour in a bowl, add margarine and rub into flour

4. Add sugar, golden syrup and nut powder/paste and mix well

5. Add water and mix into stiff dough. Roll into a ball, place on a greased tray or baking paper on a tray and flatten into a biscuit

6. Bake for 12 minutes or until slightly golden brown and firm to touch 
Open Access This article is licensed under a Creative Commons Attribution 4.0 International License, which permits use, sharing, adaptation, distribution and reproduction in any medium or format, as long as you give appropriate credit to the original author(s) and the source, provide a link to the Creative Commons licence, and indicate if changes were made. The images or other third party material in this article are included in the article's Creative Commons licence, unless indicated otherwise in a credit line to the material. If material is not included in the article's Creative Commons licence and your intended use is not permitted by statutory regulation or exceeds the permitted use, you will need to obtain permission directly from the copyright holder. To view a copy of this licence, visit http://creativecommons.org/licenses/by/4.0/.

\section{References}

1. Diagnosing and managing food allergy in children Holloway, Edward; Fox, Adam, Fitzsimons, Roisin. Practitioner; London Vol. 255, Iss. 1741.
2. Fleischer DM, Conover-Walker MK, Christie L, Burks AW, Wood RA. The natural progression of peanut allergy: resolution and the possibility of recurrence. J Allergy Clin Immunol St Louis. 2003;112(1):183-9. https://doi.org/10.1067/mai.2003.1517.

3. Australasian Society of Clinical Immunology and Allergy. Skin Prick Testing Working Party. Skin Prick testing for the diagnosis of allergic disease. Updated 2020. Available at https:// www.allergy.org.au/ASCIA HP SPT Guide 2020

4. Thalayasingam M, Noble V, Franzmann A, O’Sullivan M. Outcome of mixed nut biscuit challenge in low risk patients who are on tree nut exclusion diet. Paediatr Allergy Immunol. 2015. https://doi.org/10. 1111/pai.12437.

5. van der Valk JPM, van Wijk RG, Dubois AEJ, de Groot H, de Jong NW. Failure of introduction of cashew nut after a negative oral food challenge test in children. Paediatr Allergy Immunol. 2016. https:// doi.org/10.1111/PAI.12591.

Publisher's Note Springer Nature remains neutral with regard to jurisdictional claims in published maps and institutional affiliations. 